\title{
Correction to: Diffusion coefficient in biomembrane critical pores
}

\section{Md Mozzammel Haque ${ }^{1}$}

Published online: 8 November 2017

(C) Springer Science+Business Media, LLC 2017

\section{Correction to: J Bioenerg Biomembr}

https://doi.org/10.1007/s10863-017-9726-8

The original version of this article unfortunately contained two mistakes.

1. The Greek capital letter Theta didn't appear in the PDF version at the end in this sentence "Where the two-order in $\Theta$ represents a stable pore with a critical pore area $\Delta=\pi$ $2 / 4$." and should be corrected as "Where the two-order in $\Theta$ represents a stable pore with a critical pore area $\Delta=\pi \Theta^{2} / 4$."

2. A word "ligands" was misspelled as "legands".

The original article has been corrected.

The online version of the original article can be found at https://oi.org/ 10.1007/s10863-017-9726-8

Md Mozzammel Haque

mdmozzammelhaque@gmail.com

1 ChemiScience, Ashulia, Dhaka 1344, Bangladesh 